vents them from participating in the economic, political and cultural spheres of life.

Fraser's book is a sophisticated analysis of feminist political theory that demands a lot from its readers-but coming to terms with her arguments is well worth the effort.

Jan Kainer

York University

\title{
Angela Brintlinger and Ilya Vinitsky, eds., Madness and the Mad in Russian Culture (Toronto; Buffalo: University of Toronto Press, 2015). 344pp. Paper- back $\$ 37.95$.
}

From melancholy under Catherine the Great to the fan hysteria surrounding Vsevolod Garshin to Russian evaluations of shell shock during World War I, this collection of fifteen essays covers a vast territory. Rather than providing readers with a comprehensive history of madness, the volume offers important individual studies with each author looking at the problem from a unique angle. Hence even the madness in the title changes - the subject can be melancholy, insanity, craziness and the mental reasons behind suicide. The essays are organized in a more or less chronological order and expose the reader to the phases of mental health in Russia and the Soviet Union.

The historically-inclined essays balance the weaknesses of an empire slow to industrialize with the critical contributions Russians made to modern science. Lia Iangoulova argues that even if being sent to a zemstva (rural self-administration) asylum was a virtual death sentence, the Kazan Regional asylum was "a psychiatrist's dream" (47). Over the course of the nineteenth century, Russian law came to recognize "psychiatric examination" in a scientific manner (53). Irina Sirotkina argues that Russian psychiatrists were more willing to advocate "mild treatment of war neurotics" in World War I because of their antipathy to the war and the tsarist government. Interestingly, this sympathy can be also be ascribed to the absence of a pension system in Russia so the state did not have to worry about added financial burdens (124).

Most of the essays, however, are anchored in the tradition of literary analysis and focus on the relationship of madness to the work and lives of important authors: Catherine the Great, Pushkin, Dostoevsky, Garshin, and Chekhov have individual works examined. In keeping with literary criticism, these essays analyze the intersection of lived experience with the content of fictional works. Vsevolod Garshin, a late nineteenth-century writer who suffered from mental illness, had a cult following amongst hysteric fans. According to Robert D. Wessling, "popularized theories of mental illness combined with the literary aesthetics of the 1880 s... to generate codes of behaviour for his associates and fans" (76). In other words, the personality and the writings of Garshin had a "paralysing effect" on his fans (82). 
This back and forth between literary production and the actual insanity, however defined, dominates the volume.

With this in mind, one could hardly expect to miss a contribution on Dostoevsky's Demons. Dostoevsky is a natural benchmark for exploring madness and sprinkled throughout the volume are careful insights drawn from his other works. When Martin Miller focuses on attempts to denounce revolutionaries as insane, he draws attention to the psychopathological traits of the characters in the Demons. Miller does not deny the claim that the characters are from "real life" but he portrays Dostoevsky as a scientist who developed psychopathologies "that had not yet been legitimated in clinical textbooks" (108). Hence, the revolutionary characters were not united by "ideological agreement;" rather, common symptoms of madness influenced their actions. This was, of course, Dostoevsky's way of expressing disapproval with the revolutionary movement.

If Dostoevsky is offered medical credentials, Anton Chekhov needed no such introduction. As a practitioner of medicine, he was ineluctably drawn into the world of psychiatric care. Margareta Odesskaya indicates how his literary portrayal of asylums in Ward No. 6 undervalued the zemstvo efforts to improve a difficult situation. In the Blank Monk, Chekhov took a deeper look at megalomania and the link between genius and madness (a theme also explored later in the volume with an essay on V.P. Efroimson, a Soviet author). In this story, Odesskaya presents the "conflict between a hero inspired by his hallucinations" and those who want him to return to normal life (203). Chekhov leaves the reader with the unsettling feeling that psychiatry and society could do little for such a man.

The above excerpts do not exhaust the themes in the volume but the general literary trend is clear. The emphasis on literature suggests that the culture in the title is really defined as literary culture. This thought permits a closer look at the interdisciplinary nature of the collection. On the one hand, the volume certainly encourages a multi-layered analysis of madness. On the other hand, the interdisciplinary partners and methods are pretty standard. Whenever claims are made about language - word usage, translation, discourse - the point of reference is the linguistic turn as developed within the context of literary analysis. When Mikhail Epstein claims that "madness (bezumie) is a language," we should not be surprised (263). Since the linguistic turn has had its quinquagenary, a broader array of interdisciplinary partners would have been desirable. To be sure, doctors, psychiatrists, and other analysts appear throughout the pages but always in a secondary role. For example, we see doctors as literati creating their own discourse but their actual practice gets lost (186).

As a corollary, the volume downplays those who were incarcerated or those who had serious mental problems but did not enjoy celebrity. Mention is made of the sex maniac who tried to manipulate the legal system and of individual cases of suicide, but they are at the margins $(159,133)$. Since animal magnetism and hypnotic practices were not unknown in Russia and represented real medical alternatives 
in the West, a few words about these trends would have been desirable especially since even Russians of the third millennium continue to turn to "non-psychiatric healing practices" (296).

The collection of essays is both an excellent introduction to madness and an opportunity to probe this fascinating terrain in depth. It avoids focusing on the common story of Soviet psychiatry, a story that is well known, and therefore gives the reader the opportunity to explore alternatives. Similarly, it does not just condemn Russia for backwardness - while admitting that the Russian psychiatric profession had a late start, it indicates the important advances and attitudes developed in the Russian Empire and the Soviet Union. More importantly, it provides a complex web of viewpoints about the most complex terrain, the human mind.

Nigel Raab

Loyola Marymount University

\section{Winfried Siemerling, The Black Atlantic Reconsidered: Black Canadian Writ- ing, Cultural History, and the Presence of the Past (Montreal \& Kingston: McGill-Queen’s University Press, 2015). 560pp. Paperback \$34.95.}

Winfried Siemerling's The Black Atlantic Reconsidered is fundamentally interdisciplinary in nature, and will undoubtedly be used heavily for teaching in fields such as literature and critical race theory. Rather than providing an account of the book's uses in various fields, my focus in this review is particularly on how the book can be drawn upon by historians in a variety of geographic fields. Siemerling's work, and in particular his theories on time and memory, is of exceptional value to historians, beyond just those studying black Canada.

Siemerling's book situates black Canadian writing and history as a crucial nexus in the black Atlantic world. He also shows how this writing, from the eighteenth century onward, is simultaneously local, diasporic, transatlantic, and hemispheric in nature; while many prominent black Canadian writers from the 1960s, for instance, were born in the Caribbean, their writing is nonetheless as locally implicated as it is transnational. This conception of geography and space builds on Stuart Hall's theories on belonging and identity in diaspora, and makes a unique and powerful contribution to these ideas.

In his insightful and complex introduction, Siemerling reflects critically on the idea that black Canadian writing has been understood to embody melancholia. He argues that instead the hauntings that appear in black Canadian writing, and the wider importance of the past in contemporary black Canadian writing, speak to optimism in the form of highlighting possibilities for black futures. He draws heavily on the work of Eduoard Glissant (14) as well as Jacques Derrida (23-24) and Stuart Hall (13-15) to engage in this analysis, and these themes remain consistently prominent throughout the book. 